\title{
Nutrição mineral e extração de nutrientes de planta de milho irrigada com água salina ${ }^{1}$
}

\author{
Geocleber G. de Sousa ${ }^{2}$, Claudivan F. de Lacerda ${ }^{3}$, Lourival F. Cavalcante ${ }^{4}$, \\ Francisco V. A. G uimarães ${ }^{5}$, Maria E. de J. Bezerra ${ }^{6}$ \& G iovana L. da Silva ${ }^{7}$
}

\begin{abstract}
RESUMO
A utilização de água salina na agricultura irrigada pode causar desequilíbrio nutricional e inibição competitiva na absorção de nutrientes. 0 objetivo deste trabal ho foi avaliar os efeitos da salinidade da água de irrigação sobre 0 acúmulo, os totais extraídos e a distribuição de nutrientes em plantas de milho. 0 estudo foi conduzido em condições de campo em um Argissolo Vermelho Amarelo na estação seca, no delineamento em blocos ao acaso, com cinco repetições, de setembro a dezembro de 2007, em Fortaleza, CE. As plantas de milho foram coletadas aos 90 dias após a semeadura e realizadas as seguintes avaliações: teores, extração e distribuição de elementos minerais nas diferentes partes da planta (folha, colmo, grão e sabugo). 0 aumento da salinidade da água de irrigação aos 90 dias após a semeadura, inibiu o acúmulo de potássio nas fol has e de magnésio e fósforo nos grãos. A extração dos nutrientes e sódio pelas plantas irrigadas com água de salinidade variando de 0,8 a $3,6 \mathrm{dS} \mathrm{m}^{-1}$ obedeceu à seguinte ordem decrescente: $\mathrm{K}>$ $\mathrm{Mg}>\mathrm{Ca}>\mathrm{P}>\mathrm{Na}$; no tratamento de maior salinidade $\left(5,0 \mathrm{dS} \mathrm{m}^{-1}\right)$ a sequência de extração foi: $\mathrm{K}>\mathrm{Ca}>\mathrm{Na}>\mathrm{P}>\mathrm{Mg}$.
\end{abstract}

Palavras-chave: estresse salino, Zea mays, irrigação, elementos minerais

\section{Mineral nutrition and extraction of nutrients by corn plant irrigated with saline water}

\begin{abstract}
The use of saline water in imigated agriculture can cause nutritional imbalance and competitive inhibition in the absorption of nutrients. The objective of this study was to evaluate the effects of salinity of imigation water on the accumulation, the total absorption, and the distribution of mineral elements in maize plants. The study was conducted under field conditions in an Yellow Red Argisol in the dry season, in the randomized blocks design with five replicates during September to December 2007 in Fortaleza - CE. The maize plants were collected at 90 days after sowing, and the following assessments were made: content, extraction and distribution of mineral elements in the plant parts (leaf, stem, grain and elderberry). The increase of sal inity of imigation water at 90 days after so wing inhibited the accumulation of potassium in leaves, and corn stan and phosphorus in the grains. The extraction of nutrients and sodium by plants irrigated with saline water ranging from 0.8 to $3.6 \mathrm{dS} \mathrm{m}^{-1}$ had the following decreasing order: $\mathrm{K}>\mathrm{Mg}>\mathrm{Ca}>\mathrm{P}>\mathrm{Na}$; the treatment of higher salinity $\left(5.0 \mathrm{dS} \mathrm{m}^{-1}\right)$ the sequence extraction was: $\mathrm{K}>\mathrm{Ca}>\mathrm{Na}>\mathrm{P}>\mathrm{Mg}$.
\end{abstract}

Key words: salt stress, Zea mays, irrigation, minerals elements

\footnotetext{
1 Parte da Dissertação de Mestrado do primeiro autor apresentada ao CCA/UFC; Projeto Financiado pelo CNPq

2 Doutorando em Engenharia Agrícola, Campus do Pici, CCA/UFC, Av. Mister Hull, 2977, CEP 60455-760, Fortaleza, CE. Fone: (85) 8724-4390. E-mail: sousamsa@yahoo.com.br

3 DENA/UFC. CEP 60455-760, Fortaleza, CE. Fone (85) 3366-9127. E-mail: cfeitosa@ufc.br

${ }^{4}$ DSER/UFPB. CEP 58397-000, Areia, PB. Fone: (83) 3362-2300. E-mail: lofeca@cca.ufpb.br

${ }^{5}$ FUNCEME-CE. CEP 60455-760, Fortaleza, CE. E-mail:valderez@ufc.br

6 Mestranda em Solos e Nutrição de Plantas, Campus do Pici, CCA/UFC. CEP 60455-760, Fortaleza, CE

7 Doutoranda em Ecologia e Recursos Naturais, Campus do Pici, CC/UFC. Fone: (85) 8787-9752. E-mail: gisolos@hotmail.com
} 


\section{INTRODUÇÃO}

Em regiões de clima árido e semiarido é frequente a água conter sais solúveis em excesso, e a utilização dessas águas sem uma fração de lixiviação adequada, pode provocar a salinização dos solos, reduzindo o crescimento, o desenvolvimento das plantas e os teores de macronutrientes catiônicos (Garcia et al., 2007; Baghalian et al., 2008).

Os efeitos da salinidade da água de irrigação sobre as plantas se refletem em alterações no potencial osmótico, na toxidade dos íons e no desequilíbrio nutricional das plantas (Azevedo Neto \& Tabosa, 2000; Ferreira et al., 2007). A resposta das plantas à salinidade é um fenômeno complexo, envolvendo alterações morfológicas, fisiológicas e bioquímicas (Fougere et al., 1991; Munns, 2002).

Segundo Munns (2005) a inibição do crescimento das plantas sob salinidade ocorre por duas razões, a primeira se deve ao efeito osmótico provocado pela salinidade, que reduz a absorção de água, e a segunda se dá devido ao efeito específico dos íons ou ao excesso, que entram no fluxo de transpiração e, eventualmente, causam injúrias nas folhas, reduzindo o crescimento ou influenciando negativamente na absorção de elementos essenciais.

As interações iônicas que afetam a disponibilidade, absorção e transporte de nutrientes, são altamente complexas, mesmo na ausência de salinidade e de outros estresses. Em meios salinos essas interações se tornam ainda mais complexas em virtude das diferenças na concentração e na composição iônica dos meios salinos (água e solo) aos quais as plantas são submetidas, e das diferentes respostas das plantas, tanto em relação à salinidade como em relação à eficiência na aquisição de minerais do solo (Lacerda, 2005).

O estresse nutricional em plantas sob estresse salino pode estar associado ao acúmulo excessivo de determinados íons e à redução na aquisição de outros, em virtude das alterações na disponibilidade de nutrientes, da competição no processo de absorção e à inibição do transporte na planta (Blanco et al., 2008; Neves, et al., 2009a; Gurgel et al., 2010). Por exemplo, Ferreira et al. (2005) e Garcia et al. (2007) avaliando os efeitos da salinidade do solo sobre a nutrição mineral da cultura do milho, constataram um decréscimo na extração de $\mathrm{Ca}$, $\mathrm{Mg}$ e K. Desta forma, é possível sugerir que os mecanismos desenvolvidos para absorver, extrair, transportar e utilizar os nutrientes minerais, presentes em ambientes não salinos, podem não ser eficazes em condições salinas (Grattan \& Grieve, 1999).

O presente trabalho foi realizado com o objetivo de avaliar os efeitos da salinidade da água de irrigação sobre o acúmulo, os totais extraídos e a distribuição de elementos minerais em plantas de milho.

\section{MATERIAL E MÉTODOS}

O experimento foi conduzido em um solo do tipo Argissolo Vermelho Amarelo, segundo EMBRAPA (2006), na área experimental do Laboratório de Hidráulica e Irrigação da Universidade Federal do Ceará, Campus do PICI, em Fortaleza, Ceará. De acordo com a classificação de Köppen, o clima da região é do tipo Aw'.

O preparo da área experimental foi realizado 60 dias antes do plantio e consistiu de uma aração, seguida de gradagem. Antes da aração aplicou-se calcário na dose de 2,0 $\mathrm{Mg} \mathrm{ha}^{-1}$ necessária para corrigir a acidez do solo que apresentava $\mathrm{pH}$ de 5,3. Antes do plantio foram coletadas amostras de solo e as principais características químicas do solo, determinadas de acordo com Silva (1999), são apresentadas na Tabela 1.

O plantio foi realizado em setembro de 2007, utilizando-se sementes do milho híbrido AG 1051, que se apresenta com boa produtividade (Albuquerque et al., 2008). Após o estabelecimento das plântulas, oito dias após a semeadura, as plantas passaram a ser irrigadas com água com quatro diferentes condutividades elétricas. T1 - água com CEa de $0,8 \mathrm{dS} \mathrm{m}^{-1}$; T2 - água com CEa de 2,2 dS m ${ }^{-1}$; T3 - água com CEa de 3,6 $\mathrm{dS} \mathrm{m} \mathrm{m}^{-1}$ e T4 - água com CEa de 5,0 dS m ${ }^{-1}$.

Para o preparo das águas dos tratamentos 2, 3 e 4, utilizaram-se os sais de $\mathrm{NaCl}, \mathrm{CaCl}_{2} \cdot 2 \mathrm{H}_{2} \mathrm{O}$ e $\mathrm{MgCl}_{2} \cdot 6 \mathrm{H}_{2} \mathrm{O}$ dissolvidos na água do poço, na proporção de 7:2:1 de $\mathrm{Na}, \mathrm{Ca}$ e $\mathrm{Mg}$, respectivamente, obedecendo-se à relação entre a condutividade elétrica da água de irrigação (CEa) e sua concentração (mmolc L ${ }^{-1}=$ CE x 10), extraída de Rhoades et al. (2000).

A água foi aplicada em sulcos nivelados e fechados em turno de rega de três dias. As lâminas de irrigação foram definidas com base nos valores de evapotranspiração de referência (ETo) e obtidas através do tanque classe A, e dos coeficientes da cultura $(\mathrm{Kc})$ recomendados para os diferentes estádios fenológicos da cultura (Doorenbos \& Kassam, 1994). Adicionou-se, ainda, uma fração de lixiviação de $15 \%$ por irrigação, calculada de acordo com Ayers \& Westcot (1999).

$\mathrm{Na}$ adubação das plantas, foram utilizados 1,5 g de uréia, $8,4 \mathrm{~g}$ de superfosfato simples e $1,4 \mathrm{~g}$ de cloreto de potássio por cova, correspondente às doses de 60,30 e $30 \mathrm{~kg} \mathrm{ha}^{-1} \mathrm{de}$ $\mathrm{N}, \mathrm{P}_{2} \mathrm{O}_{5}$ e $\mathrm{K}_{2} \mathrm{O}$, respectivamente, Fernandes (1993). As doses de uréia e de cloreto de potássio foram parceladas em três aplicações, sendo a primeira aplicação efetuada no dia do plantio das plantas (fundação) sendo que as duas outras aplicações foram realizadas em cobertura (aos 25 e 40 dias após o plantio). No caso do superfosfato simples utilizou-se a dose completa durante o plantio das plantas. O delineamento experimental foi o de blocos ao acaso, com cinco repetições, totalizando 20 unidades experimentais. Cada parcela tinha 3 $\mathrm{m}$ de comprimento e cinco linhas de plantio. Foi utilizado o

Tabela 1. Atributos químicos do solo antes do plantio

\begin{tabular}{|c|c|c|c|c|c|c|c|c|c|c|c|}
\hline \multirow[t]{2}{*}{ Caracteńsisticas } & $\mathrm{MO}\left(\mathrm{g} \mathrm{kg}^{-1}\right)$ & $\mathrm{Ca}^{2+}$ & $\mathbf{K}^{+}$ & $\mathrm{Mg}^{2+}$ & $\frac{\mathrm{Na}^{+}}{\mathrm{cmol}_{\mathrm{c}} \mathrm{dm}^{-3}}$ & $\mathrm{H}^{+}+\mathbf{A l}^{3+}$ & SB & CTC & V (\%) & $\begin{array}{c}P \\
\left(\mathrm{mg} \mathrm{dm}^{-3}\right)\end{array}$ & pH \\
\hline & 8,48 & 1,5 & 0,11 & 1,1 & 0,26 & 1,15 & 2,97 & 4,12 & 71 & 10 & 6,3 \\
\hline
\end{tabular}

M.O - Matéria orgânica; SB - soma de bases $\left(\mathrm{Ca}^{2+}+\mathrm{Mg}^{2+}+\mathrm{Na}^{+}+\mathrm{K}^{+}\right) ; \mathrm{CTC}-$ capacidade de troca de cátions $-\left[\mathrm{Ca}^{2+}+\mathrm{Mg}^{2+}+\mathrm{Na}^{+}+\mathrm{K}^{+}+\left(\mathrm{H}^{+}+\mathrm{Al}^{3+}\right)\right] ; \mathrm{V}$

- Saturação por bases - $\left(\mathrm{Ca}^{2+}+\mathrm{Mg}^{2+}+\mathrm{Na}^{+}+\mathrm{K}+/ \mathrm{CTC}\right) \times 100$; o pH foi medido em extrato aquoso $(1: 2,5)$ 
espaçamento de $0,8 \times 0,2 \mathrm{~m}$, com 1600 plantas no total e uma densidade de plantio de 62500 plantas por ha.

A colheita foi realizada aos 90 DAS, sendo retiradas ao acaso, 15 plantas das três linhas centrais de cada parcela. As plantas foram separadas em limbos foliares, colmo + bainhas e espigas, acondicionadas em sacos de papel previamente identificados e levadas à estufa de ventilação forçada de ar, a $65^{\circ} \mathrm{C}$, até peso constante; todos os materiais secos foram pesados e as espigas separadas em palhas, grãos e sabugo.

As amostras secadas em estufa (folha, colmo, sabugo e grãos) e finamente trituradas em moinho tipo Wiley, foram acondicionadas em sacos de papel devidamente identificados, material este utilizado nas determinações dos teores dos elementos minerais ( $\mathrm{Na}, \mathrm{K}, \mathrm{Ca}, \mathrm{Mg}$ e $\mathrm{P}$ ).

Determinaram-se os teores de $\mathrm{Na}$ e $\mathrm{K}$ através de fotometria de chama, os teores de $\mathrm{P}$ por colorimetria e os teores de Ca e Mg por espectrofotometria de absorção atômica (Malavolta et al., 1989). Com os dados obtidos dos teores de elementos minerais, calcularam-se os totais extraídos (multiplicando-se o teor pela produção de matéria seca) e a distribuição percentual, nas diferentes partes das plantas analisadas.

Os dados de teores de $\mathrm{Na}$ e dos macronutrientes obtidos em cada nível salino da água de irrigação foram submetidos às análises de variância e de regressão, utilizando-se o programa computacional SAEG/UFV (Ribeiro Júnior, 2001).

\section{RESULTADOS E DISCUSSÃO}

\section{Teores de elementos minerais}

Os valores dos quadrados médios e da significância estatística quanto aos teores de nutrientes ( $\mathrm{Na}, \mathrm{K}, \mathrm{Ca}, \mathrm{Mg}$ e P) nas diversas partes das plantas de milho irrigado com quatro níveis de salinidade $\left(0,8 ; 2,2 ; 3,6\right.$ e $\left.5,0 \mathrm{dS} \mathrm{m}^{-1}\right)$ podem ser vistos na Tabela 2. Constatou-se, de acordo com a análise de variância, que os teores de nutrientes em quase todas as partes das plantas foram influenciados significativamente ( $\mathrm{p}$ $<0,01$ e 0,05) nas diferentes concentrações de sais na água de irrigação.

Nas folhas, principal órgão da planta em termos de avaliação nutricional, foram observados efeitos significativos para todos os nutrientes analisados, excetuando-se os teores de $\mathrm{Mg}$ e $\mathrm{P}$ no colmo das plantas a salinidade exerceu influência sobre os teores dos 5 elementos analisados no caso dos grãos observou-se que a salinidade influenciou nos teores de $\mathrm{Na}$, $\mathrm{K}$ e $\mathrm{Mg}$ e nos sabugos a salinidade influenciou nos teores de Na, Ca, K, Mg e P (Tabela 2). Ressalta-se que as variações dos teores de nutrientes aos 90 dias apos a semeadura do milho podem ser decorrentes dos processos de acumulação e mobilidade dos nutrientes dentro da planta (Taiz \& Zeiger, 2004).

Os níveis crescentes de salinidade da água de irrigação aumentaram os teores de sódio nas folhas, colmos, grãos e sabugos de milho aos 90 DAS (Figura 1). A maioria das espécies que utilizam as rotas $\mathrm{C}_{4}$ de fixação de carbono, como é o caso do milho, requer íons sódio, por estar envolvido na transferência de metabólitos entre os cloroplastos das células do
Tabela 2. Valores dos quadrados médios e da significância estatística para os teores de $\mathrm{Na}, \mathrm{K}, \mathrm{Ca}, \mathrm{Mg}$ e $\mathrm{P}$ nas diversas partes de plantas de milho irrigadas com água com quatro níveis de salinidade $\left(0,8 ; 2,2 ; 3,6\right.$ e 5,0 dS $\left.\mathrm{m}^{-1}\right)$

\begin{tabular}{|c|c|c|c|c|c|}
\hline \multirow{2}{*}{ Elemento } & \multirow{2}{*}{$\begin{array}{l}\text { Parte da } \\
\text { Planta }\end{array}$} & \multicolumn{3}{|c|}{ Quadrado Médio } & \multirow{2}{*}{ CV } \\
\hline & & Salinidade & Bloco & Resíduo & \\
\hline \multirow{4}{*}{$\mathrm{Na}$} & Folha & $0,15 *$ & $0,16^{\text {ns }}$ & 0,27 & 4,57 \\
\hline & Colmo & $1,67 * *$ & 0,79 ns & 0,62 & 11,23 \\
\hline & Grãos & $0,22 * *$ & $0,11^{\text {ns }}$ & 0,15 & 14,26 \\
\hline & Sabugo & $1,02 * *$ & $0,15^{\text {ns }}$ & 0,38 & 18,09 \\
\hline \multirow{4}{*}{ K } & Folha & $8,58 *$ & $1,38^{\text {ns }}$ & 1,54 & 8,86 \\
\hline & Colmo & $33,43 * *$ & 2,68 ns & 2,14 & 8,77 \\
\hline & Grãos & $1,29 *$ & 0,94 ns & 0,35 & 6,15 \\
\hline & Sabugo & $1,58 *$ & 0,90 ns & 0,38 & 7,29 \\
\hline \multirow{4}{*}{$\mathrm{Ca}$} & Folha & $8,17^{* *}$ & 1,7 ns & 0,61 & 7,97 \\
\hline & Colmo & $519,54 * *$ & 2,5 ns & 6,3 & 13,66 \\
\hline & Grãos & 3,74 ns & $1,71^{\text {ns }}$ & 1,11 & 16,04 \\
\hline & Sabugo & $641,5 * *$ & 2,02 ns & 0,35 & 6,64 \\
\hline \multirow{4}{*}{$\mathrm{Mg}$} & Folha & $0,94 \mathrm{~ns}$ & $0,17^{\text {ns }}$ & 0,58 & 12,67 \\
\hline & Colmo & $6,41^{* *}$ & 0,49 ns & 0,57 & 12,89 \\
\hline & Grãos & $52,96 * *$ & 0,34 ns & 0,23 & 5,82 \\
\hline & Sabugo & 40,41 ** & $0,98^{\mathrm{ns}}$ & 0,11 & 16,9 \\
\hline \multirow{4}{*}{$\mathrm{P}$} & Folha & $0,36^{\mathrm{ns}}$ & $0,32^{\text {ns }}$ & 0,15 & 18,66 \\
\hline & Colmo & $0,47 * *$ & $0,45^{\text {ns }}$ & 0,10 & 16,24 \\
\hline & Grãos & $0,29 \mathrm{~ns}$ & $0,71^{* *}$ & 0,15 & 9,24 \\
\hline & Sabugo & $0,35 * *$ & 0,12 ns & 0,74 & 14,69 \\
\hline
\end{tabular}

mesófilo e da bainha vascular das plantas (Korndorfer, 2007); no entanto, o acúmulo do íon sódio em excesso, principalmente nas folhas, resulta na inibição do crescimento (Azevedo Neto \& Tabosa, 2000; Ferreira et al. 2005), em função de sua ação tóxica sobre o metabolismo celular (Munns, 2002). Semelhante ao observado nesse trabalho, Garcia et al. (2007) e Oliveira et al. (2009) verificaram aumento da concentração de sódio na parte aérea de plantas de milho cultivado em ambientes salinos.

O aumento da salinidade da água de irrigação provocou aumento nos teores de cálcio nas folhas e colmos (Figura 2). Diferentemente dos resultados obtidos nesse trabalho, outros estudos têm demonstrado que a salinidade diminui os teores de Ca na parte aérea das plantas de milho (Azevedo Neto \& Tabosa, 2000; Garcia et al., 2007). De acordo com esses autores, o aumento do teor de sódio do meio externo ocasiona diminuição dos teores de cálcio nos tecidos das plantas de milho. Ainda segundo Cramer et al. (1994), o sódio desloca o cálcio da plasmalema das células radiculares, resultando em uma perda da integridade da membrana e efluxo citossólico de solutos orgânicos e inorgânicos.

É importante destacar que o efeito do Na sobre o Ca em condições de salinidade é verificado, principalmente quando se utiliza apenas o $\mathrm{NaCl}$ como agente estressante. No presente estudo foi utilizada uma mistura de sais de sódio, cálcio e magnésio, o que justifica, pelo menos em parte, os aumentos nos teores de cálcio, o que contraria outros estudos realizados principalmente em casa de vegetação (Azevedo Neto \& Tabosa, 2000; Costa et al., 2003; Ferreira et al., 2005). 

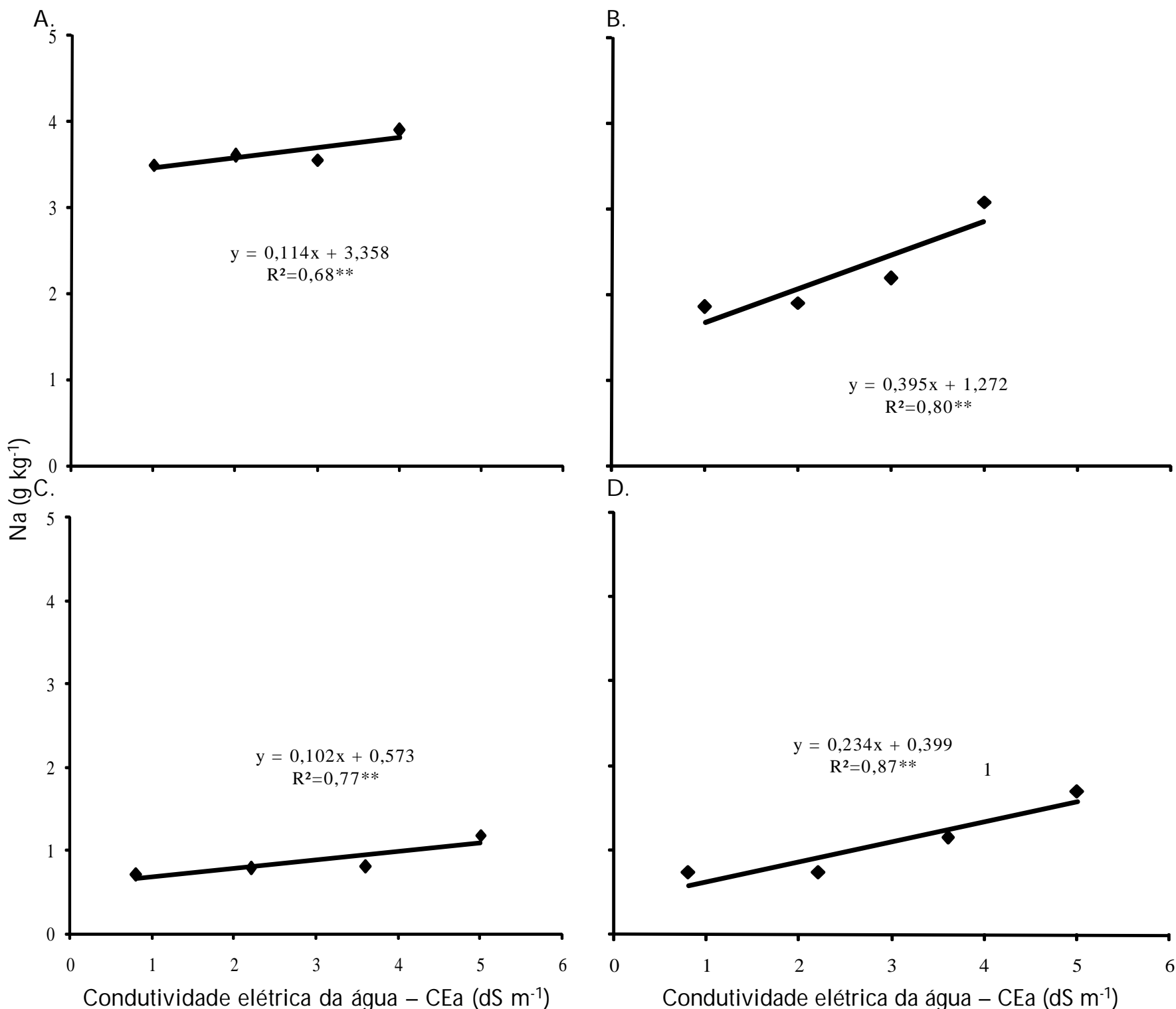

Figura 1. Teores de sódio nas folhas (A), nos colmos (B), nos grãos (C) e nos sabugos (D) de plantas de milho aos 90 DAS, em função dos níveis de salinidade da água de irrigação. Significativo ao nível de $1 \%(* *)$ e $5 \%(*)$ de probabilidade

Ao contrário do verificado para o sódio e o cálcio, o teor de potássio nas folhas, nos grãos e nos sabugos do milho, foi reduzido com o aumento dos níveis salinos da água de irrigação (Figura 3). Segundo Kawasaki et al. (1983), o aumento da concentração de sódio no meio radicular pode inibir a absorção de potássio devido a relação competitiva entre esses cátions monovalentes. Outro aspecto negativo do antagonismo do sódio com o potássio é a diminuição deste nutriente nos grãos, já que o potássio proporciona melhor qualidade dos frutos. Corroborando com este estudo, Karteji et al. 2001; 2004 também encontraram efeito similar em plantas de milho sob estresse salino.

O aumento da salinidade da água de irrigação não influenciou os teores de Mg nas folhas (Tabela 2), porém provocou aumento nos colmos e sabugos, e redução nos grãos (Figura 4). Contrariando este estudo, Azevedo Neto \& Tabosa (2000) e Garcia et al. (2007) verificaram, em plantas de milho submetidas a diferentes níveis de $\mathrm{NaCl}$ em solução nutritiva dimi- nuição dos teores de magnésio no colmo. Bosco et al. (2009) também verificaram aumento no teor de $\mathrm{Mg}$ nos caules de berinjela submetida e estresse com $\mathrm{NaCl}$. É importante destacar que a água de irrigação usada neste estudo continha fonte de magnésio $\left(\mathrm{MgCl}_{2}\right)$ e que, apesar da importância do magnésio no metabolismo vegetal ainda são escassos os estudos relativos a este nutriente em ambientes salinos, principalmente em condições de campo.

O aumento dos sais na água irrigação não influenciou os teores de $\mathrm{P}$ nos limbos foliares e nos grãos (Tabela 2), porém aumentou os teores de $\mathrm{P}$ nos colmos (Figura 5A) e diminuiu nos sabugos (Figura 5B). Este resultado diverge de outros estudos que mostraram aumento nos teores foliares de fósforo em plantas de sorgo forrageiro, feijão-de-corda e berinjela irrigadas com águas salinas (Lacerda et al., 2006; Sousa et al., 2007; Bosco et al., 2009), enquanto outros mostram redução nos teores foliares de fósforo em plantas de milho sob estresse salino (Ferreira et al., 2007). Nos colmos Azevedo Neto 

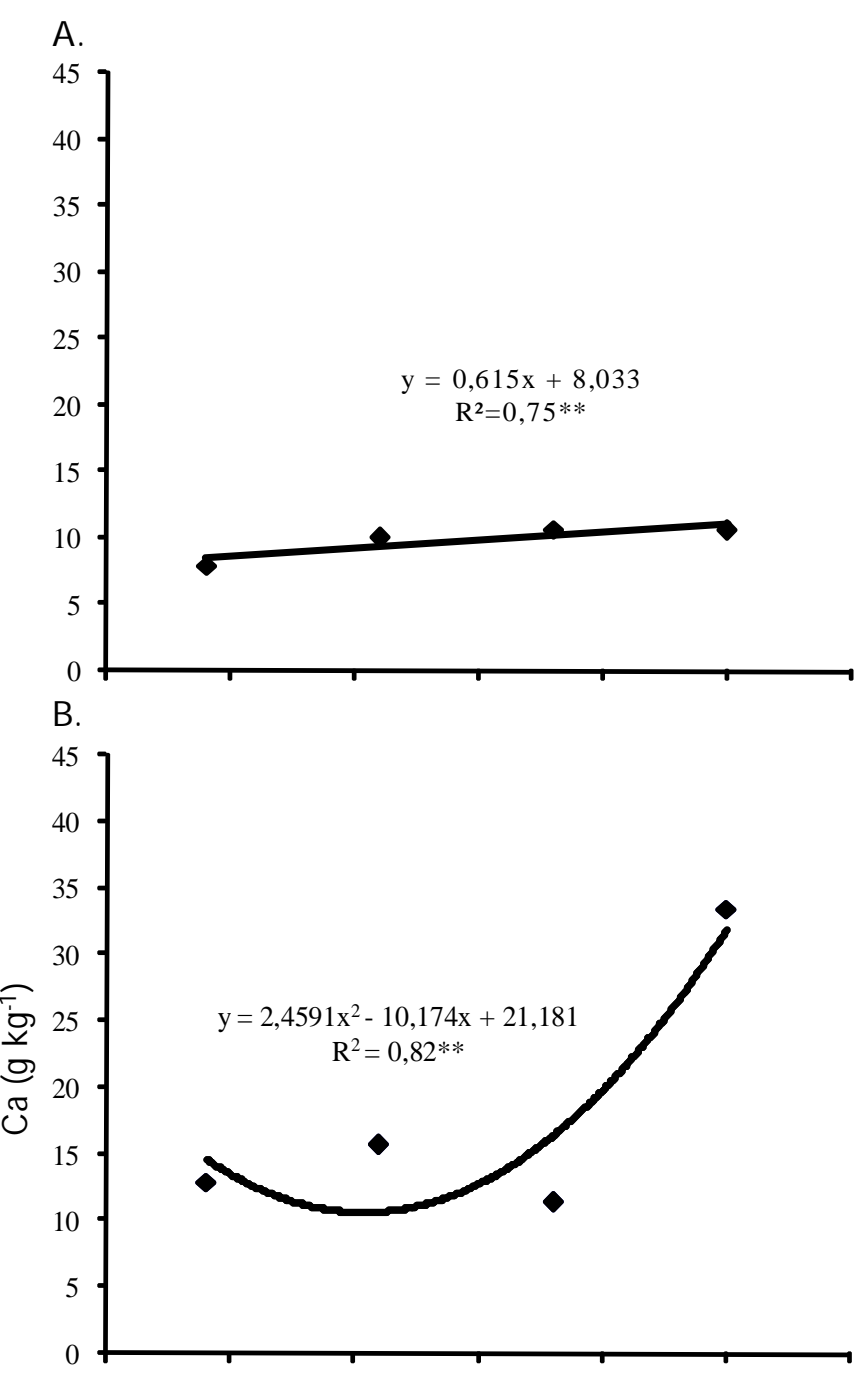

C.

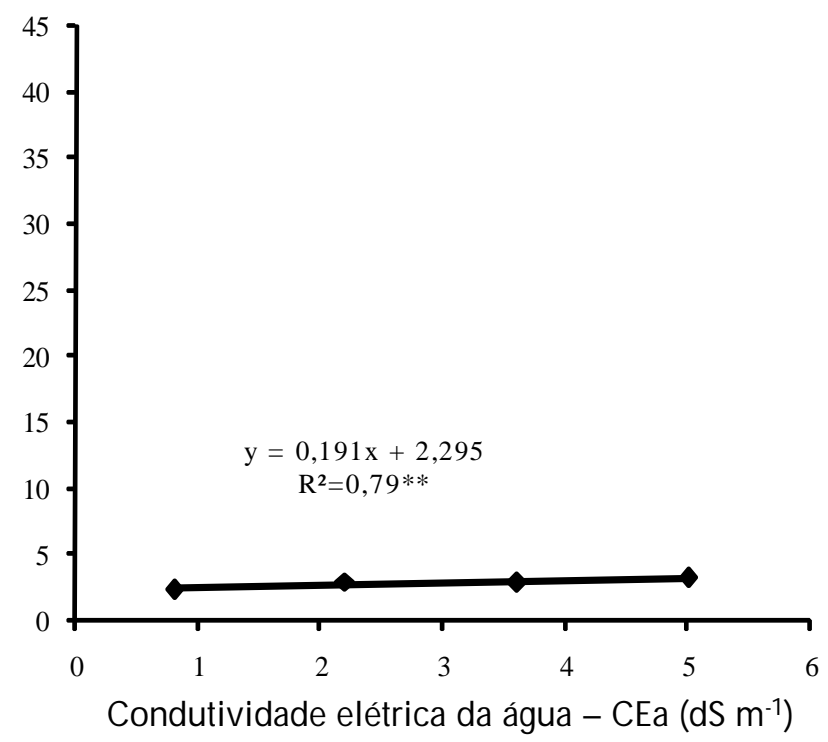

Figura 2. Teores de cálcio nas fol has (A), nos colmos (B) e nos sabugos (C) de plantas de milho aos 90 DAS, em função dos níveis de salinidade da água de irrigação. Significativo ao nível de $1 \%\left({ }^{* *}\right)$ de probabilidade

\& Tabosa (2000) e Garcia et al. (2005) obtiveram resultados diferentes dos deste estudo, com a cultura do milho em ambiente salino sob condições de casa de vegetação.
De acordo com Ferreira et al. (2007), a salinidade diminui a concentração de fósforo no tecido das plantas em razão dos efeitos da força iônica, que reduzem a atividade de fosfato na solução do solo, e pela diminuição da solubilidade deste nutriente com o aumento dos níveis de $\mathrm{NaCl}$. Além disso, alguns resultados experimentais evidenciam que os teores de $\mathrm{P}$ em plantas cultivadas em ambientes salinos variam durante o crescimento e o desenvolvimento da cultura (Lacerda et al., 2006; Neves et al., 2009a). Salienta-se que a interação entre a salinidade e a nutrição mineral de fósforo em plantas é complexa e dependente da espécie, da concentração de fósforo no solo e dos tipos de sais e nível de salinidade da água de irrigação (Grattan \& Grieve, 1999), o que pode justificar as discrepâncias entre os resultados obtidos no presente estudo e os obtidos por outros autores.

\section{Extração de nutrientes e de sódio do solo pelas plantas de milho}

O aumento da concentração salina da água de irrigação influenciou nos conteúdos de nutrientes minerais (Tabela 3). Em condições de baixa salinidade da água de irrigação $(0,8$

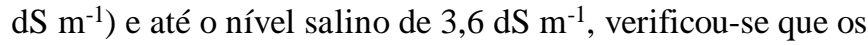
nutrientes analisados foram extraídos na seguinte ordem decrescente: $\mathrm{K}>\mathrm{Mg}>\mathrm{Ca}>\mathrm{P}>\mathrm{Na}$ (Tabela 4). Hiroce et al. (1989) encontraram resultados diferentes em relação a esta sequência de extração na cultura do milho, porém as plantas foram irrigadas com água de baixa salinidade.

Tabela 3. Valores dos quadrados médios e da significância estatística do conteúdo de nutrientes em plantas de milho irrigadas com quatro níveis de salinidade $(0,8 ; 2,2 ; 3,6$ e 5,0 dS $\left.m^{-1}\right)$

\begin{tabular}{ccccc}
\hline \multirow{2}{*}{ Elementos } & \multicolumn{4}{c}{ Quadrados médios } \\
\cline { 2 - 5 } & Tratamentos & Blocos & Resíduos & CV \\
$\mathrm{Na}$ & $32,15^{*}$ & 9,55 & 3,77 & 9,72 \\
$\mathrm{~K}$ & $724,12^{*}$ & 191,78 & 70,39 & 5,95 \\
$\mathrm{Ca}$ & $192,18^{*}$ & 32,61 & 39,26 & 20,42 \\
$\mathrm{Mg}$ & $1121,41^{* *}$ & 33,34 & 48,93 & 19,11 \\
$\mathrm{P}$ & $72,19^{*}$ & 28,93 & 16,94 & 16,71 \\
\hline
\end{tabular}

$*, * *$ Significativo pelo teste $\mathrm{F}$ a 5 e $1 \%$ respectivamente; $\mathrm{CV}(\%)$ Coeficiente de Variação

Comparando-se os tratamentos, verificou-se que o aumento da concentração de sais na água de irrigação reduziu os totais extraídos de $\mathrm{P}, \mathrm{Ca}, \mathrm{K}$ e $\mathrm{Mg}$ (Tabela 4). A diminuição dos totais extraídos desses nutrientes em plantas sob estresse salino se deve principalmente à inibição do crescimento provocado sobremaneira pelos efeitos osmóticos e tóxicos, e do excesso de sais na zona radicular (Lacerda, 2005). Tendências similares foram constatados por Costa et al. (2008) em

Tabela 4. Totais extraídos de $\mathrm{Na}, \mathrm{Ca}, \mathrm{K}, \mathrm{Mg}$ e P, em kg ha-1, em plantas de milho irrigadas com água salina

\begin{tabular}{|c|c|c|c|c|c|}
\hline CEa (dS $\left.\mathrm{m}^{-1}\right)$ & $\mathrm{Na}$ & K & $\mathrm{Ca}$ & $\mathrm{Mg}$ & $\mathbf{P}$ \\
\hline 0,8 & $17,71 \pm$ & $149,4 \pm 6,2$ & $38,1 \pm 3,5$ & $53,5 \pm 4,7$ & $28,5 \pm 2,0$ \\
\hline 2,2 & $19,0 \pm 0,8$ & $151,3 \pm 5,1$ & $33,0 \pm 3,4$ & $35,4 \pm 2,7$ & $26,3 \pm 2,1$ \\
\hline 3,6 & $19,7 \pm 1,0$ & $137,3 \pm 3,4$ & $27,5 \pm 1,7$ & $40,3 \pm 2,4$ & $24,1 \pm 1,4$ \\
\hline 5,0 & $23,6 \pm 1,5$ & $125,4 \pm 2,1$ & $24,0 \pm 1,7$ & $17,3 \pm 1,1$ & $19,6 \pm 1,3$ \\
\hline
\end{tabular}

${ }^{1}$ valores médios \pm erro padrão da média 

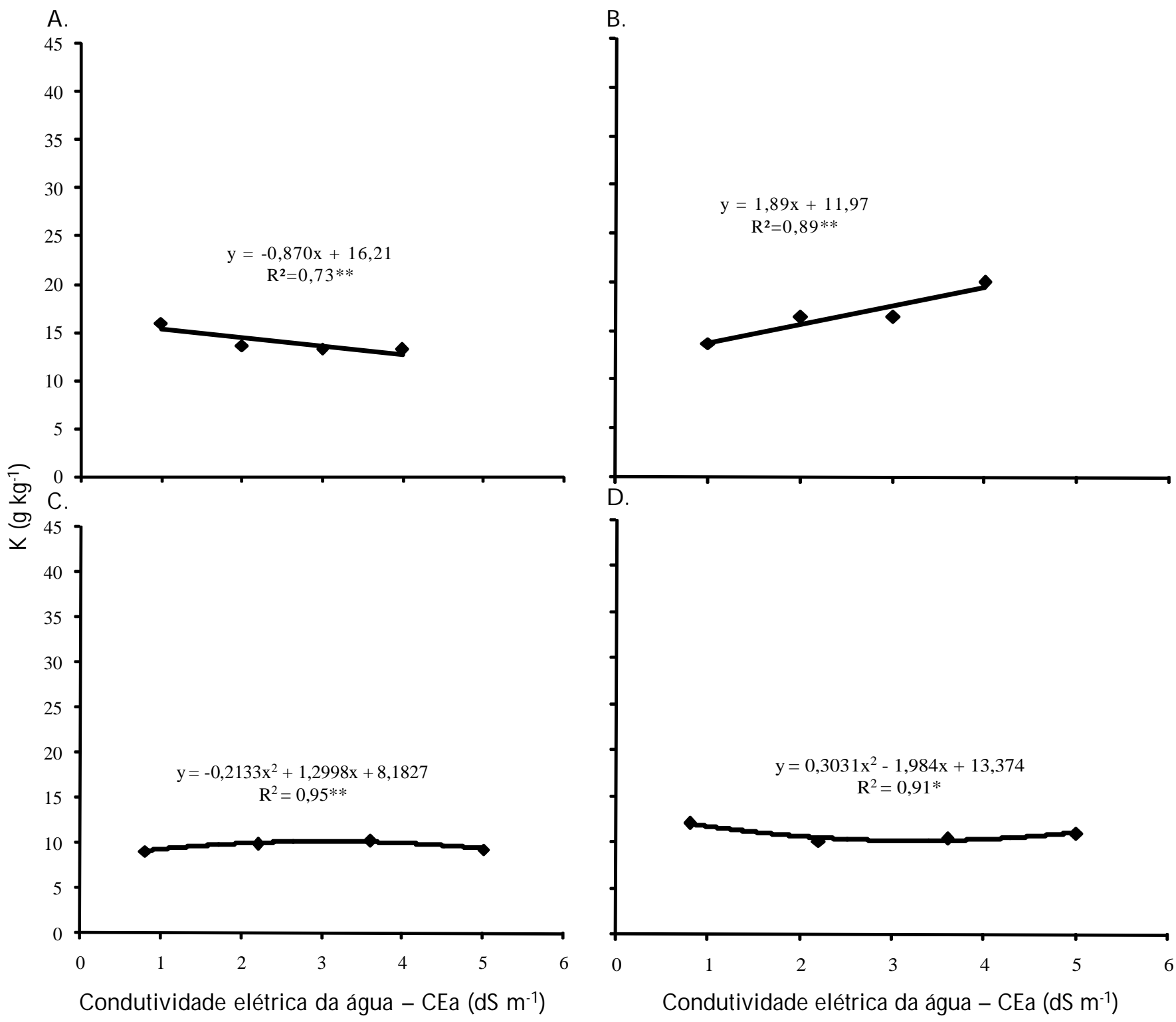

Figura 3. Teores de potássio nas fol has (A), nos colmos (B), nos grãos (C) e nos sabugos (D) de plantas de milho aos 90 DAP, em função dos níveis de salinidade da água de irrigação. Significativo ao nível de $1 \%(* *)$ e $5 \%(*)$ de probabilidade

Tabela 5. Distribuição de $\mathrm{Na}, \mathrm{K}, \mathrm{Ca}, \mathrm{Mg}$ e $\mathrm{P}$, nas partes vegetativas e reprodutivas de plantas de milho irrigadas com água salina

\begin{tabular}{cccccc}
\hline \multirow{2}{*}{ Parte da planta } & \multicolumn{5}{c}{ Elementos minerais - $\mathbf{~ k g ~ h a}^{-1}$} \\
\cline { 2 - 7 } & $\mathbf{N a}$ & $\mathbf{K}$ & $\mathbf{C a}$ & $\mathbf{M g}$ & $\mathbf{P}$ \\
Folha & $4,94 \mathrm{c}(6,41)^{1}$ & $19,56 \mathrm{~d}(17,26)$ & $0,02 \mathrm{c}(0,06)$ & $0,75 \mathrm{a}(2,15)$ & $2,93 \mathrm{~b}(13,63)$ \\
Colmo & $68,49 \mathrm{a}(88,89)$ & $51,73 \mathrm{a}(45,65)$ & $3,01 \mathrm{~b}(10,07)$ & $1,82 \mathrm{a}(5,22)$ & $1,94 \mathrm{bc}(9,02)$ \\
Sabugo & $0,75 \mathrm{c}(0,97)$ & $5,88 \mathrm{e}(5,18)$ & $1,98 \mathrm{bc}(6,62)$ & $0,43 \mathrm{a}(1,23)$ & $0,4 \mathrm{~cd}(1,86)$ \\
Grãos & $3,17 \mathrm{c}(4,11)$ & $36,14 \mathrm{~b}(31,89)$ & $24,87 \mathrm{a}(83.23)$ & $31,85 \mathrm{~b}(91,39)$ & $16,22 \mathrm{a}(75,47)$ \\
\hline
\end{tabular}

Médias seguidas de mesmas letras nas colunas, para parte da planta, não diferem estatisticamente pelo teste de Tukey (Pe”0, 05); valores entre parênteses representam as percentagens em cada parte da planta

condições de casa vegetação, na cultura do amaranto e por Neves et al. (2009b) a campo, na cultura do feijão-de-corda.

Com relação ao $\mathrm{Na}$, ainda se observa variação de extração entre os tratamentos estudados. No maior nível de salinidade, os nutrientes foram extraídos na seguinte ordem decrescente: $\mathrm{K}>\mathrm{Ca}>\mathrm{Na}>\mathrm{P}>\mathrm{Mg}$. Aumento no conteúdo de $\mathrm{Na}$ também foi observado por Neves et al. (2004), Barbosa et al.
(2005), Garcia et al. (2007) e por Silva et al. (2008) ao trabalharem com mudas de umbuzeiro, plantas de milho, banana e meloeiro, respectivamente, em condições de casa de vegetação.

Distribuição de nutrientes e de sódio do solo pelas plantas de milho

$\mathrm{Na}$ distribuição dos elementos minerais na planta aos 90 DAS apenas o K não foi afetado pelos tratamentos (Tabela 5). 
A.

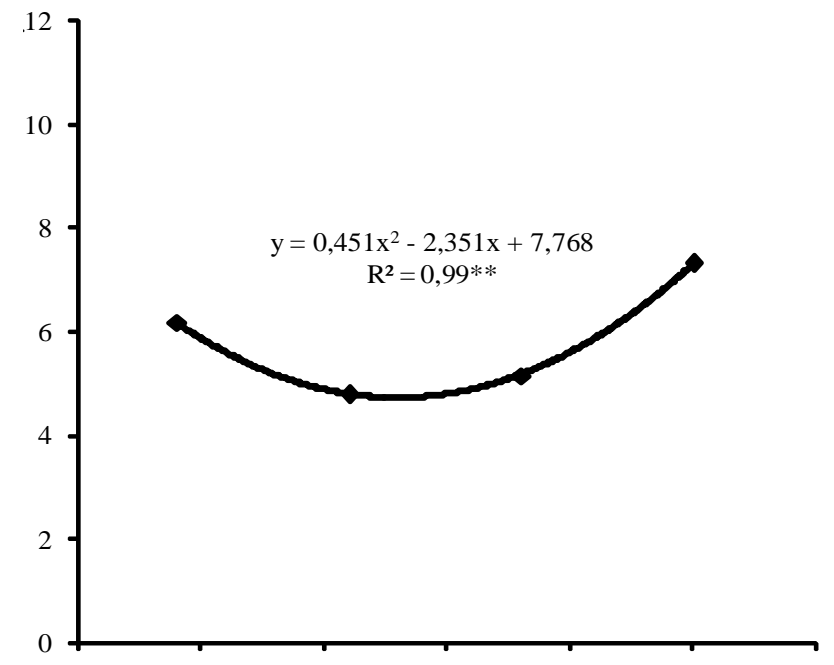

B.

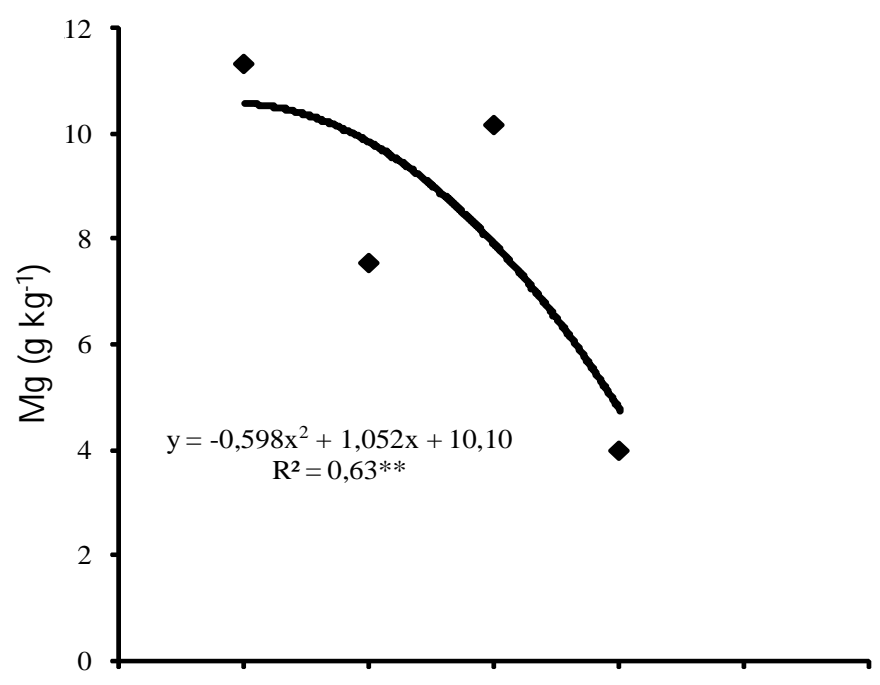

C.

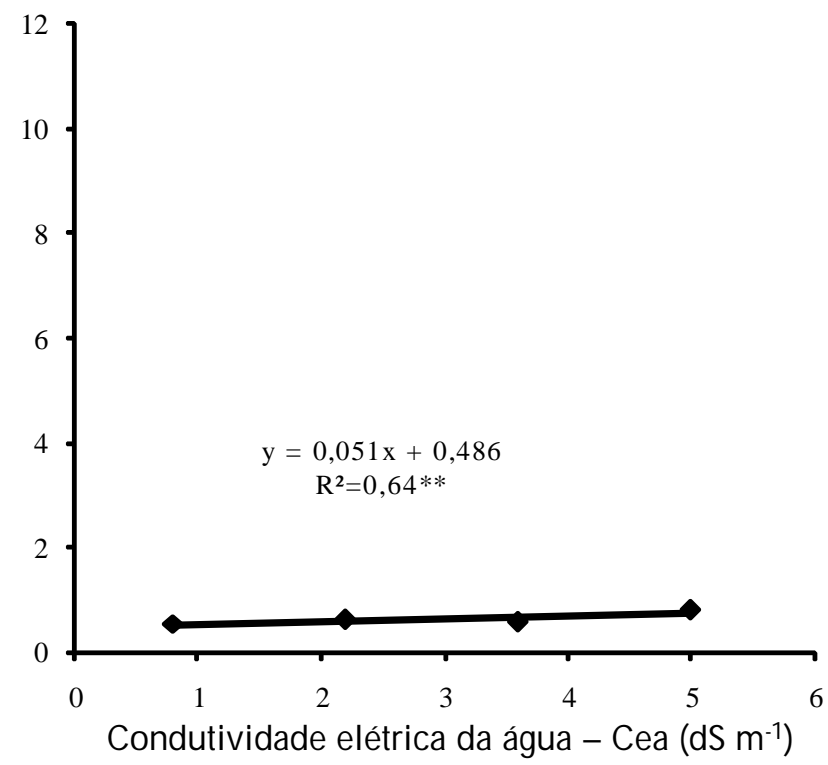

Figura 4. Teores de magnésio no colmo (A), nos grãos (B) e nos sabugos $(C)$ de plantas de milho aos 90 DAP, em função dos níveis de salinidade da água de irrigação. significativo a nível de $1 \%(* *)$ e $5 \%(*)$ de probabilidade
Entre as diferentes partes analisadas (folha, colmo, sabugo e os grãos), os minerais Na e K (Tabela 5) permaneceram acumulados preferencialmente nas partes vegetativas, apresentando valores superiores a $60 \%$.

Com relação ao íon potencialmente tóxico $(\mathrm{Na})$ Trindade et al. (2006) constataram aumento nos limbos foliares de planta de sorgo forrageiro até o vigésimo dia após a semeadura em solução nutritiva com $\mathrm{NaCl}(75 \mathrm{mM})$ em casa de vegetação. Nestas mesmas condições Silva et al. (2009) obtiveram um acúmulo excessivo de $\mathrm{Na}$ nas folhas de pinhão manso, chegando a $661 \%$ na dose mais elevada de $\mathrm{NaCl}(100 \mathrm{mM})$; já com o (K) Costa et al. (2008) e Silva et al. (2009) notaram dados semelhantes em amaranto e pinhão-manso, sendo ambos os estudos em condições de casa de vegetação.

Salienta-se que, com esta distribuição dos nutrientes para as partes vegetativas os restos culturais da cultura do milho se tornam importantes, tanto como cobertura do solo como na ciclagem de nutrientes.

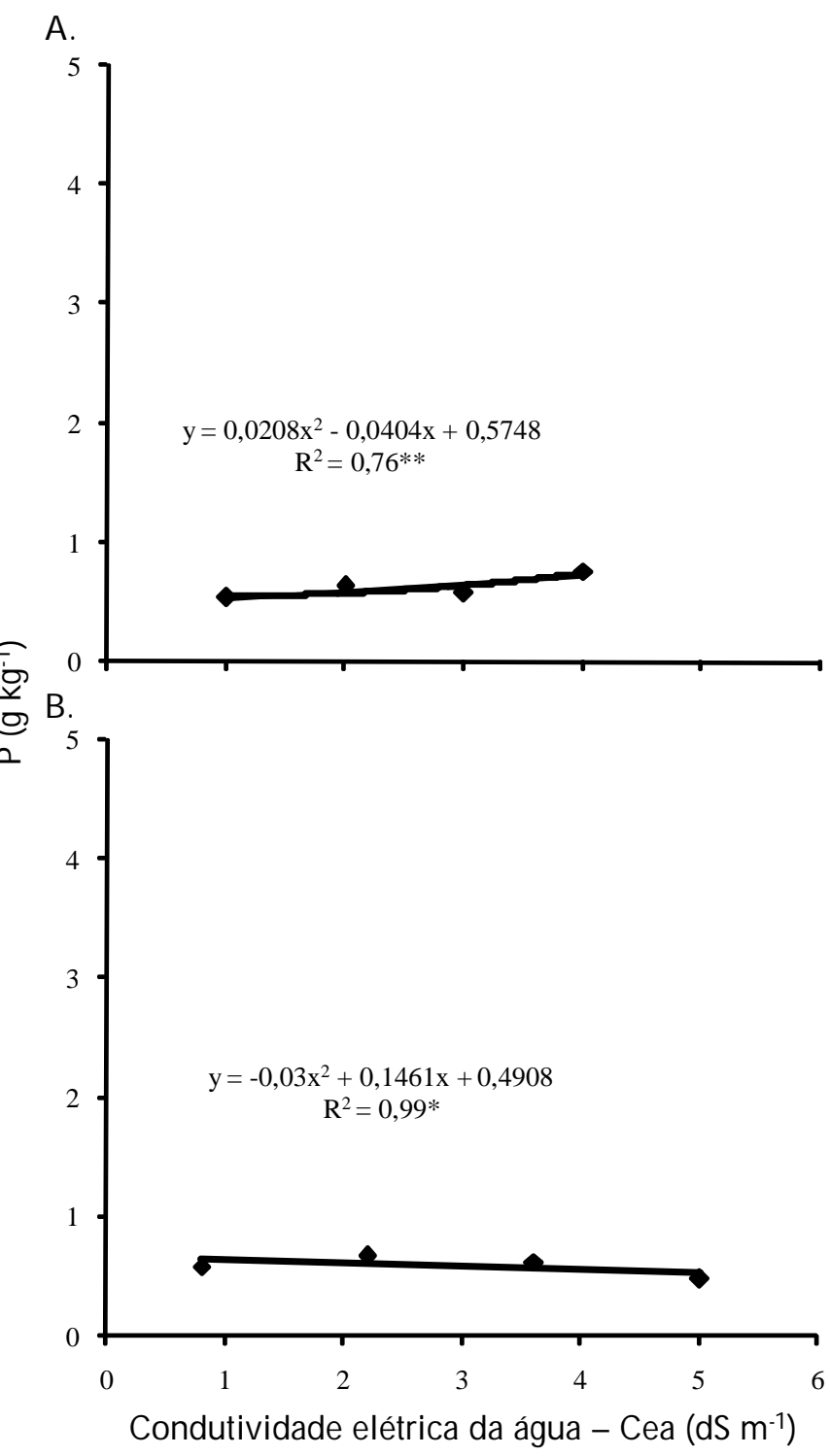

Figura 5. Teores de fósforo nos colmos (A) e nos sabugos (B) de plantas de milho aos 90 DAP, em função dos níveis de salinidade da água de irrigação. significativo a nível de $1 \%(* *)$ e $5 \%(*)$ de probabilidade 
Com relação aos outros nutrientes, $\mathrm{Ca}, \mathrm{Mg}$ e $\mathrm{P}$ se distribuíram para os grãos, sendo exportados em maiores proporções pela cultura do milho aos 90 dias após a semeadura (DAS) (Tabela 5). Tendências semelhantes as do P, foram observadas por Neves et al. (2009b) em feijão-de-corda sob estresse salino, em condições de campo.

\section{CONCLUSÕES}

1. O aumento da salinidade da água de irrigação aos 90 dias após a semeadura, aumentou os teores de $\mathrm{Na}$ e $\mathrm{Ca}$ e reduziu os teores de $\mathrm{K}$ nos limbos foliares.

2. A extração dos nutrientes e sódio pelas plantas irrigadas com água de salinidade variando de 0,8 a $3,6 \mathrm{dS} \mathrm{m}^{-1}$ obedeceu à seguinte ordem decrescente: $\mathrm{K}>\mathrm{Mg}>\mathrm{Ca}>\mathrm{P}>\mathrm{Na}$; no tratamento de maior salinidade $\left(5,0 \mathrm{dS} \mathrm{m}^{-1}\right)$ a sequência de extração foi: $\mathrm{K}>\mathrm{Ca}>\mathrm{Na}>\mathrm{P}>\mathrm{Mg}$.

3. A salinidade provocou redução da extração dos elementos minerais: $\mathrm{K}, \mathrm{Ca}, \mathrm{Mg}$ e $\mathrm{P}$.

4. Os elementos minerais $\mathrm{Na}$ e $\mathrm{K}$ permaneceram nas partes vegetativas enquanto o $\mathrm{Ca}, \mathrm{Mg}$ e $\mathrm{P}$, foram exportados em maiores proporções para os órgãos reprodutivos.

\section{LITERATURA CITADA}

Albuqueruqe, C. J. B.; Pinho, R. G. V.; Borges, I. D.; Souza Filho, A. X.; Fiorini, I. V. A. Desempenho de híbridos experimentais e comerciais de milho para produção de milho verde. Revista Ciência e Agrotecnologia, v.32, n.3, p.768-775, 2008.

Ayers, R. S.; Westcot, D. W. A qualidade da água na agricultura. Campina Grande: UFPB, 1999. 153p.

Azevedo Neto A. D.; Tabosa J. N. Estresse salino em plântulas de milho: Parte II - Distribuição dos macronutrientes catiônicos e suas relações com o sódio. Revista Brasileira de Engenharia Agrícola e Ambiental, v.4, n.2, p.165-171, 2000.

Baghalian, K.; Haghiry, A.; Naghavi, M. R.; Mohammadi, A. Effect of saline irrigation water on agronomical and phytochemical characters of chamomile (Matricaria recutita L.). Scientia Horticulturae, v.116, p.437-441, 2008.

Barbosa, S. C. S.; Bastos, A. L.; Reis, S.; Costa, J. K. M.; Costa, J. P. V da.; Calheiros, C. B. M. Crescimento e absorção de nutrientes em bananeira irrigada com águas salinas. Revista Brasileira de Engenharia Agrícola e Ambiental, v.9, p.343-346, 2005.

Bosco, M. R. O.; Oliveira, A. B.; Hernandez, F. F. F.; Lacerda, C. F. de. Influência do estresse salino na composição mineral da berinjela. Revista Ciência Agronômica, v.40, n.2, p.157-164, 2009.

Blanco, F. F.; Folegatti, M. V.; Henriques Neto, D. Doses de N e K no tomateiro sob estresse salino: I. Concentração de nutrientes no solo e na planta. Revista Brasileira de Engenharia Agrícola e Ambiental, v.12, n.1, p.26-33, 2008.

Costa, D. M. A.; Melo, N. S.; Ferreira, S. R.; Dantas, J. A. Con-

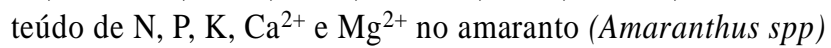
sob estresse salino e cobertura morta. Revista Ciência Agronômica, v.39, n.2, p.209-216, 2008.
Costa, P. H. A.; Silva, J. V.; M. A.; Enéas Filho, J.; Prisco, J. T.; Gomes Filho, E. Crescimento e níveis de solutos orgânicos e inorgânicos em cultivares de Vigna unguiculata submetidos à salinidade. Revista Brasileira de Botânica, v.26, n.3, p.289297, 2003.

Cramer, G. R.; Alberico, G. J.; Schmidt, C. Leaf expansion limits dry matter accumulation of salt-stressed maize. Australian Journal of Plan Physiology, v.21, p.675-692, 1994.

Doorenbos, J.; Kassam, A. H. Efeito da água no rendimento das culturas. Campina Grande: UFPB, 1994. 306p. Estudos da FAO, Irrigação e Drenagem, 33.

EMBRAPA - Empresa Brasileira de Pesquisa Agropecuária. Sistema Brasileiro de Classificação de Solos. 2.ed. Rio de Janeiro: Embrapa Solos, 2006. 306p.

Fernandes, V. L. B. Recomendações de adubação e calagem para o Estado do Ceará. Fortaleza: UFC, 1993. 248p.

Ferreira, P. A.; Garcia, G. O.; Neves, J. C. L.; Miranda, G. V.; Santos, D. B. Produção relativa do milho e teores folheares de nitrogênio, fósforo, enxofre e cloro em função da salinidade do solo. Revista Ciência Agronômica, v.38, n.1, p.7-16, 2007.

Ferreira, P. A. Garcia, G. O.; Santos, D. B.; Oliveira, F. G.; Neves, C. L. Estresse salino em plantas de milho: II - Macronutrientes aniônicos e suas relações com o sódio. Revista Brasileira de Engenharia Agrícola e Ambiental, v.9, p.11-15, 2005.

Fougere, F. L.; Rudulier, D.; Streeter, J. G. Effects of salt stress on amino acid, organic acid, and carbohydrate composition of roots, bacteroids, and cytosol of alfafa (Medicago sativa L.). Plant Physiology, v.96, p.1228-1236, 1991.

Garcia, G. O.; Ferreira, P. A.; Miranda, G. V.; Neves, J. C. L.; Moraes, W. B.; Santos, D.B. Teores foliares dos macronutrientes catiônicos e suas relações com sódio em plantas de milho sob estresse salino. Idesia, v.25, p.93-106, 2007.

Garcia, G. O. Ferreira, P. A.; Santos, D. B.; Oliveira, F. G.; Miranda, G. V. Estresse salino em plantas de milho: I - macronutrientes aniônicos e suas relações com o cloro. Revista Brasileira de Engenharia Agrícola e Ambiental, v.9, p.26-30, 2005.

Grattan, S. R.; Grieve, C. M. Salinity-mineral relations in horticultural crops. Scientia Horticulturae, v.78, p.127-157, 1999.

Gurgel, M. T.; Uyeda, C. A.; Gheyi, H. R.; Oliveira, F. H. T. de.; Fernandes, P. D.; Silva, F. V. da. Crescimento de meloeiro sob estresse salino e doses de potássio. Revista Brasileira de Engenharia Agrícola e Ambiental, v.14, n.1, p.310, 2010.

Hiroce, R.; Furlani, A. M. C.; Lima, M. Extração de nutrientes na colheita por populações e híbridos de milho. Campinas: IAC, 1989. 24p. Boletim Técnico, 17.

Katerji, N.; Hoorn, J. W. van; Hamdy, A.; Mastrorilli, M. Salt tolerance of crops according to three classication methods and examination of some hypothesis about salt tolerance. Agricutural Walter Management, v.47, p.1-8, 2001.

Katerji, N.; Hoorn, J. W. van; Hamdyc, A.; Mastrorilli, M. Comparison of corn yield response to plant water stress caused by salinity and by drought. Agricutural Walter Management, v.65, p.95-101, 2004. 
Kawasaki, T.; Akiba, T.; Moritsugu, M. Effects of high concentrations of sodium chloride and polyethylene glycol on the growth and ion absorption in plants: I. Water culture experiments in a greenhouse. Plant and Soil, v.75, p.75-85, 1983.

Korndorfer, G. H. Elementos benéficos. In: Fernandes, M. S. Nutrição mineral de plantas. Viçosa: SBCS, 2007. cap.14, p.355-370.

Lacerda, C. F. de. Interação salinidade x nutrição mineral. In: Nogueira, R. J. C.; Araújo, E. L.; Willadino, L. G.; Cavalcante, U. (ed.). Estresses ambientais: danos e benefícios em plantas. Recife: UFRPE, 2005, p.127-137.

Lacerda, C. F. de.; Morais, M. M. M.; Prisco, J. T.; Gomes Filho, E.; Bezerra, M. A. Interação entre salinidade e fósforo em plantas de sorgo forrageiro. Revista Ciência Agronômica, v.37, n.3, p.258-263, 2006.

Malavolta, E.; Vitti, G. C.; Oliveira, S. A. Avaliação do estado nutricional das plantas. Piracicaba: POTAFOS, 1989. 208p.

Munns, R. Comparative physiology of salt and water stress. Plant, Cell and Environment, v.25, n.2, p.239-250, 2002.

Munns, R. Genes and salt tolerance: bringing them together. New Phytologist, v.167, n.3, p.645-663, 2005.

Neves, A. L. R.; Lacerda, C. F. de.; Guimarães, F. V. A.; Gomes Filho, E.; Feitosa, D. R. C. Trocas gasosas e teores de minerais no feijão-de-corda irrigado com água salina em diferentes estádios. Revista Brasileira de Engenharia Agrícola e Ambiental, v.13, p.873-881, 2009a.

Neves, A. L. R.; Lacerda, C. F. de.; Guimarães, F. V. A.; Hernandez, F. F. F.; Silva, F. B. da.; Prisco, J. T.; Gheyi, H. R. Acumulação de biomassa e extração de nutrientes por plantas de feijão-decorda irrigadas com água salina em diferentes estádios de desenvolvimento. Revista Ciência Rural, v.39, n.3, p.758-765, 2009 b.

Neves, O. S. C.; Carvalho, J. G.; Rodrigues, C. R. Crescimento e nutrição mineral de mudas de umbuzeiro (Spondias tuberosa Arruda Câmara.) submetidas a níveis de salinidade em solução nutritiva. Revista Ciência e Agrotecnologia, v.28, n.1, p.997-1006, 2004.
Oliveira, F. A.; Medeiros, J. F. de.; Oliveira, M. K. T.; Lima, C. J. G. S.; Almeida Júnior, A. B.; Amâncio, M. G. Desenvolvimento inicial do milho-pipoca irrigado com água de diferentes níveis de salinidade. Revista Brasileira de Ciências Agrárias, v.4, n.2, p.149-155, 2009.

Rhoades, J. P.; Kandiah, A.; Mashali, A. M. Uso de águas salinas para a produção agrícola. Campina Grande: UFPB, 2000. 117p. Estudos FAO 48.

Ribeiro Júnior, J. I. Análises estatísticas no SAEG. 1.ed.Viçosa: UFV, 2001. 301p.

Silva, E. N.; Silveira, J. A. G.; Fernandes, C. R. R.; Dutra, A.T.B.; Aragão, R.M. Acúmulo de íons e crescimento de pinhão-manso sob diferentes níveis de salinidade. Revista Ciência Agronômica, v.40, n.2, p.240-246, 2009.

Silva, F. C. Manual de análises químicas de solos, plantas e fertilizantes. Brasília: Embrapa Comunicação para Transferência de Tecnologia, 1999. 370p.

Silva, M. O.; Freire, M. B. G. S.; Mendes, A. M. S.; Freire, F.J.; Sousa, C.E.S.; Góes, G. B. Crescimento de meloeiro e acúmulo de nutrientes na planta sob irrigação com águas salinas. Revista Brasileira de Engenharia Agrícola e Ambiental, v.12, n.6, p.593-605, 2008.

Sousa, R. B.; Lacerda, C. F. de.; Amaro Filho, J.; Henandez, F. F. F. Crescimento e nutrição mineral do feijão-de-corda em função da salinidade e da composição iônica da água de irrigação. Revista Brasileira de Ciências Agrárias, v.2, n.1, p.75-82, 2007.

Taiz, L.; Zeiger, E. Fisiologia vegetal. 3.ed. Porto Alegre: ARTMED, 2004. 719p.

Trindade, A. R.; Lacerda, C. F. de.; Gomes Filho, E.; Bezerra, M. A.; Prisco, J. T. Influência do acúmulo e distribuição de íons sobre a aclimatação de plantas de sorgo e feijão-de-corda, ao estresse salino. Revista Brasileira de Engenharia Agrícola e Ambiental, v.10, n.4, p.804-10, 2006. 